\title{
HIV/AIDS Vaccine Design and Strategies
}

\section{Rupali Saxena*, Gourav Mishra, Batul Diwan and Archana Tiwari}

School of Biotechnology, Rajiv Gandhi Proudyogiki Vishwavidyalaya, Airport Bypass Road, Bhopal, Madhya Pradesh, India

\begin{abstract}
Acquired Immuno Deficiency Syndrome or AIDS was first recognized in the early 1980's. Although, with the use of antiretroviral medication, the life expectancy of an HIV infected patient can be elongated temporarily, but there is neither a known cure nor a vaccine for AIDS. This paper reviews the approaches undertaken in developing a preventive mechanism against HIV. Animal models were selected for HIV-1 vaccine development and strategies were developed where isolates of HIV-1 were taken from patients and injected in chimpanzees, but these failed to prove as a hope. Subsequently epitope driven vaccines that target the global variability of HIV was introduced. To serve this purpose computer driven methods for increasing the efficiency of vaccines like Epi-Assembler and Vaccine CAD were developed. Inducing production of broadly reactive and neutralizing antibodies could also potentially counteract HIV-1 diversity. HIV-1 Virus like Particles (VLPs) consists of viral gag proteins that self-assemble into particular structures analogous in size and morphology to immature HIV-1 particles. As a non-infectious, replication - deficient particles, the VLPs are much safer compared to traditional vaccines.
\end{abstract}

Keywords: Acquired Immuno Deficiency Syndrome; Human Immunodeficiency Virus; Vaccine CAD; Epi-Assembler; Virus like particles

\section{Introduction}

Acquired Immune Deficiency Syndrome or AIDS was first recognized in the early 1980's. AIDS has already infected around 60 million people and led to the deaths of more than 25 million people around the world, making it one of the most lethal syndrome of the human history [1]. It is considered a pandemic disease by the World Health Organization (WHO) and is prevalent all over the world (Figure 1). According to the annual reports of the Joint United Nations Program on HIV and AIDS (UNAIDS) it was reckoned that 31.6 million-35.2 million people were living with AIDS at the end of 2010. The percentage of people living with AIDS has also substantially increased $(\sim 17 \%)$ from what it was in the year 2001. The annual reports also revealed the fact that there were approximately 2.4 million-2.9 million novel HIV infections at the end of the year 2010 [2].

The need for an efficient and an effective defense mechanism against AIDS has never been greater as it is now. Although, with the use of antiretroviral medication, the life expectancy of an HIV infected patient can be elongated temporarily, but there is neither a known cure nor a vaccine for AIDS. This paper reviews the progress and current approaches undertaken in developing a preventive mechanism for HIV, and thereafter suggests a way to confront the issue by focusing

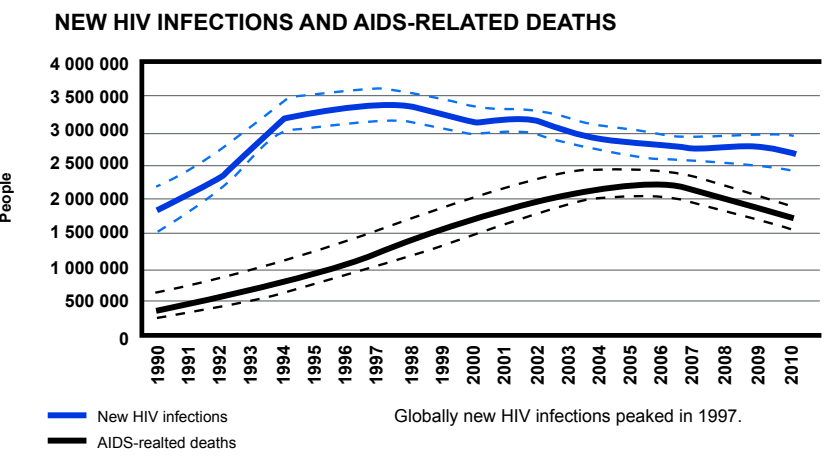

Figure 1: HIV infections and AIDS related death - There were 2.7 million [2.4 million-2.9 million] new HIV infections in 2010, including an estimated 390000 [340 000-450 000] among children New during 1990 to 2010 [2]. on various vaccine development approaches for HIV, specifically concentrating on the treatment of HIV-1 (Figure 1).

\section{Human immunodeficiency virus}

AIDS is caused by a virus called Human Immunodeficiency Virus (HIV). This virus is a member of the Retroviridae family, which has a unique ability of replicating in even non-diving cells, and it has one of the most efficient gene delivery system (Figure 2). It belongs to the genus Lentivirus, which belongs to the Retroviridae family.

Developing a defense mechanism against HIV either by the host

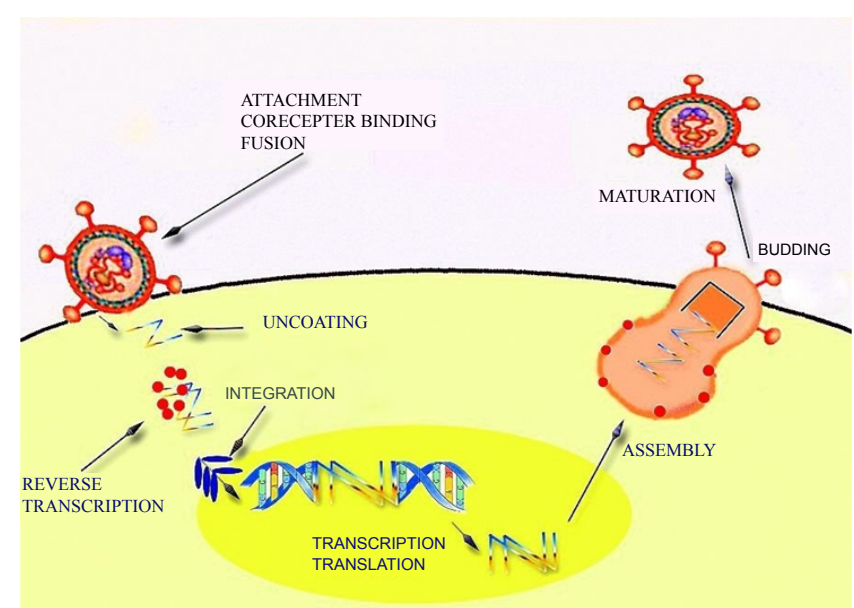

Figure 2: HIV-1 life cycle - The HIV-1 life cycle lasts one day in normal conditions. The early steps begin with the attachment of the virion at the cell surface, and finish with the integration of the proviral DNA into the host genome. The succeeding late part of the viral replication extends until virion release.

*Corresponding author: Rupali Saxena, School of Biotechnology, Rajiv Gandhi Proudyogiki Vishwavidyalaya, Bhopal, MP, E-mail: rupalionline00@gmail.com

Received May 23, 2013; Accepted june 24, 2013; Published june 28, 2013 Citation: Saxena R, Mishra G, Diwan B, Tiwari A (2013) HIV/AIDS Vaccine Design and Strategies. J Vaccines Vaccin 4: 190. doi:10.4172/2157-7560.1000190

Copyright: ( 2013 Saxena R, et al. This is an open-access article distributed under the terms of the Creative Commons Attribution License, which permits unrestricted use, distribution, and reproduction in any medium, provided the original author and source are credited. 
immune system or by any form of vaccines or drugs is an enigmatic task because HIV has a variety of escape mechanism, which it uses to protect itself. It tricks the host's immune system by rapidly mutating its genome, so that the immune system of the host is unable to build a strong immune response against it. The virus also keeps on attacking CD4+ T cells and causes immune system failure in the host body. It may also keep it protected inside the host body by residing in an inactive form [3]

Features of HIV-1 that helps in escaping immune detection are-

- Surface Env protein escapes antibody recognition as it possesses variable loops, $\mathrm{N}$-linked glycosylation, conformational flexibility and presence of glycan shield over highly immunogenic epitopes.

- Persistently replicates in the infected individual and keeps on attacking CD $4+$ T cells.

- Rapidly mutates during infection and thus escapes immune recognition and have extensive viral clade and sequence diversity.

- Persist indefinitely as latent proviral DNA, capable of replicating in individuals at a later time.

- Route of transmission is through mucosal surfaces also.

\section{Types of HIV virus}

There are two types of HIV found to infect humans till now, HIV1 and HIV-2. The strains of HIV-1 have been classified into a major group (Group $\mathrm{M}$ ) and some minor groups, which are then further classified into subtypes [4] (Figure 3).

\section{Classification of HIV-1 isolates}

The majority of HIV-1 isolates belong to group M which further consists of nine different subtypes and circulating recombinant forms (CRF's). In contrast, HIV-2 has been found to have only eight different groups. Among these, group A and group B cause major pandemics in humans [4] (Figure 3).

Understanding the difference between HIV-1 and HIV-2 is very crucial for designing an effective vaccine.

- The importance of apprehending the difference lies in the fact that HIV-2 is not much infectious and takes time to spread when

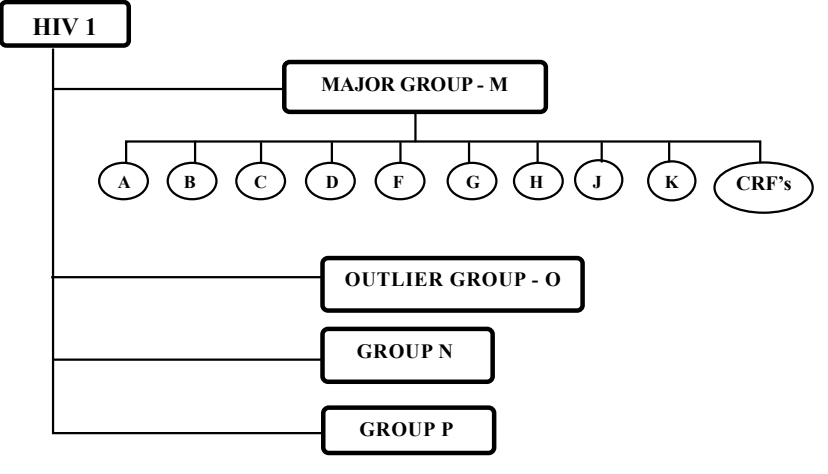

Figure 3: Classification of HIV-1 isolates - The majority of HIV-1 isolates belong to group $M$ which further consists of nine different subtypes and circulating recombinant forms (CRF's). In contrast, HIV-2 has been found to have only eight different groups. Among these, group A and group B cause major pandemics in humans [4]. compared to HIV- 1, and its prevalence is majorly restricted to West Africa. On the contrary HIV- 1 affected patients are encountered worldwide.

- HIV -2 also induces broadly reactive neutralizing antibodies in the infecting person.

- Transmission capability of HIV -2 is reasonably poor when compared with the exceedingly infectious behavior of HIV 1 .

- Less genetic variants of HIV -2 have been found when compared with varied forms of HIV-1.

- It has been observed that most of the patients suffering from HIV-2 have normal CD4+ T cell counts and the activation of immune response is also found to be lessened [5-8]

These differences may be due to the obscure nature of the strong immune responses generated against HIV-2 in the patient's body as compared to weak immune response generated against HIV-1 in the host body. Helena Barroso et al. investigated the reason for the differences in immune response generated against HIV-1 and HIV2 based on the statistical analysis of amino acid content of both the HIV types [4]. Studies have revealed the fact that strong cytotoxic responses against Env and Gag proteins of HIV-2 are generated in infected individuals and as a consequence production of heterologous neutralizing antibody response starts in the infected patient [9-13]. Thus apprehending the difference in amino acid content of crucial HIV proteins in HIV-1 and HIV-2 might help in initiating the same kind of strong immune response against HIV-1 in infected persons.

The time duration of initial infection to final stage in case of HIV-2 infection is much attenuated as compared to HIV-1 infection which quickly spreads throughout the host body. This difference in immunological response is expected to be associated with the lower state of immune activation in HIV-2, which may be related to the immunosuppressive activity of the C2-V3-C3 envelope region [14-16]

HIV -1 is found to be genetically more diverse than HIV -2 in the envelope region comprising $\mathrm{C} 2, \mathrm{~V} 3$ and $\mathrm{C} 3$ region. To confirm this further, statistical analysis was performed on HIV-1 and HIV-2 infected patients worldwide. Helena Barroso et al. took HIV-2 sequences from Portugal, belonging to group A, and the majority of HIV-1 sequences belonging to subtype B (75\%) followed by subtypes G, C and F, CRF02_ AG and CRF14_BG [4].

On comparing the amino acid diversity in the $\mathrm{C} 2, \mathrm{~V} 3$ and $\mathrm{C} 3$ regions of HIV-1 and HIV-2 by Shannon's entropy [17] studies confirmed that these regions are more variable in HIV-1 than in HIV-2. Entropy results also revealed the fact that HIV-1 possesses high entropy as compared to HIV-2 in each separate region. The region with higher mean entropy was $\mathrm{C} 3$ in both viruses for HIV-1 and also for HIV-2. V3 region was found to be the least entropic region both in HIV forms. Amino acids with high entropy were principally found to be present in the $\mathrm{C} 3$ region of both viruses and there were more highly entropic amino acids in $\mathrm{C} 3$ in HIV-1 than in HIV-2 both in the Portuguese and Control datasets. It has been recently found that HIV-2 displays a faster evolutionary rate in the envelope gp125 and C2-V3-C3 region than HIV-1 in patients who are at an advanced stage of disease $[18,19]$.

\section{Vaccines}

Vaccines are the medical product designed to activate immune system of the recipient in order to control or prevent infection. In case of HIV-1, mostly preventive vaccines are being developed. These 
vaccines are designed to protect normal population from getting a HIV infection. Preventive vaccines are widely used to prevent diseases like the flu, chicken pox, measles, mumps, rubella, polio, and hepatitis A and B. Different types of preventive vaccines include subunit vaccines, recombinant vector vaccine, DNA vaccine.

Apart from vaccine development against HIV-1, many antiretroviral drugs have been developed for treating affected individuals since 1996. However treatment alone will not be able to stop the spread of HIV1. Presently more than 33.3 million people are living with AIDS, and nearly 2.6 million people are getting newly infected [20]. Moreover these drugs stabilize the patient's symptoms but do not cure the patient completely. It also does not help in prevention of AIDS in people with undiagnosed HIV infections. Drugs need to be taken life-long and have short as well as long term side effects. They are expensive and not easily available everywhere $[21,22]$. Thus development of a safe, effective and affordable HIV vaccine is the only way to control the spread of HIV-1.

\section{Previous vaccine development approach}

Due to the complexity and high pathogenicity of the HIV-1 virus, there is an urgent need to develop novel strategies and approaches to vaccinate against it. Since the late 90's development of a successful vaccine strategy came into play utilizing the principles of conventional vaccine development.

\section{Animal models}

Animal models selected for HIV-1 vaccine development were mostly chimpanzees and macaques $[23,24]$. Various vaccine strategies were developed where epitopes of HIV-1 were taken from patients and injected in chimpanzees. Scientists found that HIV-1 replicated at a low level and the traces of viral RNA was not detectable in the plasma of infected animals, but the cost of such an approach was very high and availability of female chimpanzee was also very less (Table 1). To further improve the approach, scientists focused on Simian Immunodeficiency Viruses (SIVs). In some isolates it was found that these viruses replicate rigorously and induce AIDS like symptoms such as loss of CD4+ T cells in the host, deficient immune system leading to opportunistic infections and lymphomas. Therefore they used these viruses for infecting Asian Macaque Monkeys and studied the response to the vaccine [25].

Though the SIV viruses induce AIDS like disease and have nucleotide sequence homology with HIV [26], there are major difference found in SIV and HIV-1. The nature of the envelope of SIV is quite different from the HIV-1 that restricts the use of SIV in macaque monkeys to study the effect of envelope based vaccines. Chimeric constructs of SIV and HIV-1 known as simian/human immunodeficiency viruses (SHIVs) were constructed. These viruses had the HIV-1 envelope proteins expressed on the SIV backbone [27-30]. But these chimeric construct failed to prove as a hope because the loss of $\mathrm{CD} 4+\mathrm{T}$ cell was caused due to opportunistic infections and not by the virus attack [31]. The

\begin{tabular}{|l|l|l|}
\hline Species Targeted & Virus Used & \multicolumn{1}{c|}{ Disadvantages } \\
\hline \multirow{2}{*}{ Chimpanzees } & HIV-1 & $\begin{array}{l}\text { - Limited Availability of animal } \\
\text { - Costly approach }\end{array}$ \\
\hline \multirow{2}{*}{ Macaques } & SIV & $\begin{array}{l}\text { - Different envelope sequences as compared } \\
\text { to HIV-1 }\end{array}$ \\
\cline { 2 - 3 } & SHIV & $\begin{array}{l}\text { - Envelope epitopes were also different } \\
\text { response when used as a vaccine when com- } \\
\text { pared to HIV-1 immune response kinetics }\end{array}$ \\
\hline
\end{tabular}

Table 1: Problems using nonhuman primates during vaccine development. time of disease progression, replicative capacity and other parameters were also significantly different when compared with the pathology of HIV progression in infected humans [31,32]. Macaques also show evidence of different neurological response to SIV and SHIV. Both these responses are different from the human response. Subspecies of macaque exhibit variability in their vulnerability to the nervous system effects of the virus [33].

\section{Other preventive hiv-1 vaccine design}

Due to the escape mechanisms against immune system and unique features of HIV-1, traditional vaccine designs were not of much success. These strategies have proved be successful against many other diseases and pathogens but failed to provide any positive result against HIV-1 (Table 2).

Types of Experimental HIV vaccines based on conventional approaches:

- Peptide vaccine

- Recombinant subunit protein vaccine

- Live vector vaccine

- DNA vaccine

\section{Recent Advances}

Due to the absence of a vaccine that can prevent HIV infection, stringent research was started to develop a vaccine that delays or prevents the progression of HIV infection which could be an important intervention to curtail the current global epidemic of HIV. Recently large scale clinical study- RV144 showed some modest response (31\%) in reduction of HIV-1 infection [34]. RV144 vaccine consisted of live recombinant viral vector ALVAC-HIV-1, consisting proteins $\mathrm{gag} / \mathrm{pol} /$ env as prime vaccine followed by booster injections carrying gp120 region (AIDSVAX B/E) as protein boost (Table 3). More than 16,000 people were subjected to trial of RV144 in Thailand. This vaccine targeted both humoral and cell mediated immune response and vaccine recipients exhibited antibody dependent cell mediated cytotoxicity responses [35,36]. Another large scale clinical study, HVTN 505, also targeted the humoral and cellular immune responses. It consisted of multiclade HIV-1 DNA plasmid (EnvA, EnvB, EnvC, gagB, polB, nefB) followed by booster dose of recombinant adenovirus vector (Ad5 EnvA, EnvB, EnvC, gag/polB). The studies involve HIV-1 uninfected, adenovirus type 5 seronegative, circumcised men who have sex with

\begin{tabular}{|c|l|l|}
\hline SI. No. & \multicolumn{1}{|c|}{ Vaccine type } & \multicolumn{1}{|c|}{ Characteristics / Problems } \\
\hline 1. & $\begin{array}{l}\text { Subunit vaccines with } \\
\text { adjuvants (Env epitopes+ } \\
\text { MF59) }\end{array}$ & $\begin{array}{l}\text { Improved but limited antibody response, } \\
\text { homologous protection in animal models }\end{array}$ \\
\hline 2. & $\begin{array}{l}\text { Subunit vaccines with } \\
\text { adjuvants } \\
\text { (Tat/Nef epitopes+ AS01B) }\end{array}$ & $\begin{array}{l}\text { Improved responses in some of the animal } \\
\text { models }\end{array}$ \\
\hline 3. & Subunit gp41 vaccines & $\begin{array}{l}\text { Elicits only mucosal immunity in animal } \\
\text { models }\end{array}$ \\
\hline 4. & DNA vaccines & $\begin{array}{l}\text { Elicits mostly CD4+ T-cell response, } \\
\text { improved potency ensured by better DNA } \\
\text { delivery methods like electroporation. }\end{array}$ \\
\hline 5. & $\begin{array}{l}\text { Live recombinant vaccines } \\
\text { using vectors }\end{array}$ & $\begin{array}{l}\text { Mainly elicits CD8+ response and less } \\
\text { CD4+ response, immunogenicity hampered } \\
\text { in individuals who are pre-immune to } \\
\text { vectors, even repeated doses resulted in } \\
\text { limited impact. } \\
\text { When used in combination with gp120 } \\
\text { proteins, elicits protection in humans. }\end{array}$ \\
\hline
\end{tabular}

Table 2: Types of conventional vaccines against HIV-1. 


\begin{tabular}{|c|c|c|}
\hline Vaccine & Vaccine Components & Trial Result \\
\hline $\begin{array}{l}\text { VAX004 } \\
\text { (AIDSVAX B/B) }\end{array}$ & Recombinant gp 120 & No efficacy seen \\
\hline VAX003 (AIDSVAX B/E) & Recombinant gp 120 & No efficacy seen \\
\hline STEP (MRKAd5 HIV-1) & rAd5 (gag, pol, nef) & $\begin{array}{l}\text { No efficacy + Enhance- } \\
\text { ment of infection }\end{array}$ \\
\hline $\begin{array}{l}\text { RV144 } \\
\text { (ALVAC-HIV-1 } \\
\text { AIDSVAX B/E) }\end{array}$ & $\begin{array}{l}\text { Prime - } \\
\text { Subtype B and A/E } \\
\text { ALVAC-HIV-gag-pr-gp41- } \\
\text { gp120 (canarypox vector) } \\
\text { Boost - } \\
\text { Subtypes B \& E gp120 } \\
\text { (subunit proteins) }\end{array}$ & Modest efficacy (31.2\%) \\
\hline HVTN 505 & $\begin{array}{l}\text { Prime- } \\
\text { Multiclade HIV-1 DNA plas- } \\
\text { mid (EnvA, EnvB, EnvC, } \\
\text { gagB, polB, nefB) } \\
\text { Boost- } \\
\text { Recombinant adenovirus } \\
\text { vector (Ad5 EnvA, EnvB, } \\
\text { EnvC, gag/polB). }\end{array}$ & $\begin{array}{l}\text { Under phase } 2 \text { studies } \\
\text { [38] }\end{array}$ \\
\hline
\end{tabular}

Table 3: Clinical trials against HIV [37].

men. Along with the current approaches for vaccine design, focus has now shifted to reverse vaccinology or in silico approaches for a fast and reliable vaccine against HIV-1 [37].

\section{HIV vaccine development by computer aided design}

In the year 2005, scientist came up with the approach of computer aided drug designing against HIV-1. They introduced the concept of designing epitope driven vaccines that target the global variability of HIV. The scientists developed computer driven methods for speeding up the process of vaccine development. These methods include the use of Epi-Assembler which derives "Immunogenic Consensus Sequence" (ICS) epitopes from multiple viral variants, and Vaccine CAD, which reduces junctional immunogenicity when epitopes are aligned in a string-of-beads format for insertion into a DNA expression vector [38].

In this research 20 consensus sequences were isolated from HIV-1 peptides that were found to be immunogenic. There immunogenicity was confirmed computationally by the Epi - Assembler. The core 9-mer contained in these consensus peptides was conserved in approximately 105 to 2250 individual HIV-1 strains. Nineteen of the twenty ICS epitopes (95\%) evaluated in this study was confirmed in ELISpot assays using peripheral blood monocytes obtained from 13 healthy HIV-1 infected subjects. Twenty five ICS peptides (all 20 of the peptides evaluated in this study and 5 additional ICS epitopes) were then aligned in a pseudo protein string using "VaccineCAD", an epitope alignment tool that eliminates immunogenicity created by the junctions between the epitopes. They reordered the construct to reduce the immunogenicity of the junctions between epitopes as measured by EpiMatrix, an epitope mapping algorithm. The reordered construct was also a more effective immunogen in vivo when tested in HLA-DR transgenic mice.

However the research work did not proceed to HLA typing for each of the subjects used for this lab scale study. Thus this study did not throw light on the relationship between the HLA binding motifs contained within the ICS peptides and the HLA haplotype of the study subjects. Further studies and research work are required to substantiate the extent to which these predicted epitopes were recognized by a $\mathrm{T}$ cell. The nature of the HLA class I or class II restriction required for a proper T cell response is also yet to be studied [39].

\section{Genetic diversity considerations for vaccine design}

The genetic diversity of HIV-1 across the globe is a major challenge for developing an HIV vaccine. To facilitate immunogen design, it is important to characterize clusters of commonly targeted T-cell epitopes across different HIV clades. For examining the conserved sequences present in cross clades, a team of scientist examined $39 \mathrm{HIV}$ 1 clade C infected individuals for IFN- $\gamma$ Gag-specific T-cell responses using five sets of overlapping peptides, two sets matching clade $\mathrm{C}$ vaccine candidates derived from strains from South Africa and China, and three peptide sets corresponding to consensus clades A, B, and D sequences [40]. Previous results have shown that HIV-specific T-cells are cross-reactive among different HIV clades but with a preference for the infecting clade $[41,42]$.

The results from these studies demonstrated that within a single individual, some HIV peptides were exclusively recognized in the clade $\mathrm{C}$ sequence variants (CDu422 and $\mathrm{CCH}$ ), whilst others were uniquely recognized in the clades $B, A$ and $D$ peptide variant. The recognition of clades $\mathrm{B}, \mathrm{A}$ and $\mathrm{D}$ peptide variants and not the corresponding clade $\mathrm{C}$ peptide variants is of importance, as it demonstrates that using a single peptide reagent set leads to a considerable number of responses being missed when investigating T-cell immune responses [43,44].

These findings are of interest, since a previous study demonstrated no increase in epitope recognition when using the center of the tree (COT) and most common recent ancestor (MRCA) peptide sequences in addition to clade B consensus peptides, in a clade B HIV-infected population [45].

Further characterization of reactive peptides in the study identified highly cross-reactive peptides with low intra- and interclade diversity, as shown by their lower entropy scores. Peptides that were recognized in two or more variant forms had significantly lower entropy scores when compared to peptides recognized once across the peptide sets. The pattern of recognition observed in the mutually recognized peptides may imply that HLA alleles restricting these peptides are driving mutations in the epitopes, as shown by loss of recognition of certain variants. Further characterization of the mutually recognized peptides identified other key factors including TAP and MHC binding and proteasomal cleavage as playing a role in the recognition of specific variants and not others. This may

Illustrate the evolution of HIV due to T-cell pressure in HLA class I-restricted epitopes [44,46-50].

\section{Virus like particles (VLPs)}

Recently a major approach came into light which focused to exploit the conserved regions of HIV-1 proteins by overcoming viral immune evasion. gp120 consists of combination of conserved and variable domains. It have five conserved domain namely C1- C5 which are separated by variable domains- V1- V5 [51]. The envelope (transmembrane) protein gp120 co-receptor binding site can also act as target [52-55]. Inducing production of broadly reactive neutralizing antibodies could also potentially counteract HIV-1 diversity. Many antibodies like PG9, PG16 target even the conserved subdomain within the V1/V2 region. PGT 121- PGT123 and PGT 125-131 are potent enough to recognize the conserved base of $\mathrm{V} 3$ domain and interestingly antibodies against these regions are the one to be elicited first in HIV-1 infection [56,57]. These potential solutions for HIV-1 vaccine development could be potentially realized by exploiting prophylactic HIV-1 virus-like particle (VLP) vaccines [58]. 
HIV-1 VLPs consists of viral gag proteins that self-assemble into particular structures analogous in size and morphology to immature HIV-1 particles. As a non-infectious, replication - deficient particles, the VLPs are much safer compared to traditional vaccines made by chemically inactivated or attenuated live viruses. The different forms of VLPs have distinct properties [59-62].

Studies have shown that the immune system responds well to particular antigens that are similar to immature HIV-1 viruses. VLPs antigens are processed and present antigens through the major histocompatibility complex (MHC) class II pathway as well as the MHC class I endogenous pathway, inducing both CD4+ and CD8 T-cell-mediated immune responses [63-65].

In the recent developmental studies, the construction of VLPs was done by co-transfecting two kinds of plasmids into HEK293 cells to obtain a mammalian cell line that efficiently and stably expresses the HIV-1 structural proteins Gag, pol, and Env. The VLPs was seen to induce specific humoral and cellular immune responses after immunization, without any adjuvant [66].

Features of VLPs:

- VLPs express multiple viral epitopes that stimulate a diverse set of immune responses, without many of the deleterious effects of a live-attenuated virus.

- Potential for activating both endogenous and exogenous antigens processing pathways, leading to presentation of viral peptides by MHC class I and class II molecules.

- VLPs may be more cost efficient than co-inoculating multiple single gene vaccines for future Phase I clinical trials.

- The ability of VLPs to bind and enter cells expressing appropriate receptors. HIV-1 VLPs are able to bind to CD4 and chemokine receptors via gp120, and to enter into professional antigen presenting cells such as macrophages and dendritic cells (both cell types express CD4 and CCR5).

- Cell-free VLPs bound with antibodies can be taken up by phagocytic cells via Fc receptors, thus increasing MHC class II presentation [67].

Further the recombinant Gag, pol and Env proteins have similar structures to that of the wild HIV-1, additional work is required to fully understand how this approach could be used for advanced clinical applications.

\section{T Cell based vaccine}

The previous vaccine attempts mainly focused on eliciting antibody response in patients, but now due to the failures or inefficiency of this approach, focus has been shifted to $\mathrm{T}$ cell based vaccines. These vaccines are expected to control virus replication rather than preventing infection because they target infected cells by recognizing the viral proteins presented on major histocompatibility complex (MHC) proteins [68]. Thus the main aim of these vaccines is to control viremia. A T cell based vaccine consists of epitopes of surface proteins and inside the virion. These DNA vaccines work by introducing the viral antigens to T cells through MHC complex class I and class II. The immunogenicity of these vaccines can be enhanced by new DNA delivery methods [69]. Poxvirus, adenovirus and cytomegalovirus vectors are some of the vectors that can be used in $\mathrm{T}$ cell based vaccine [70]. Other than these replication incompetent adenoviruses have also been used that expresses HIV-1 immunogens and elicits CD4+ and CD8+ T cells response in recipient individual [69].

\section{Conclusion}

The basic idea behind all HIV vaccines is to encourage the human immune system to fight against HIV. The immune system employs a highly prolific defense mechanism that includes antibodies and numerous phagocytic cells. Early vaccine research mainly focused on making the immune system competent in producing antibodies that would block HIV entering human cells. However, vaccines designed with this concept failed in clinical trials because the antibodies worked only against lab-cultured HIV, not against the wild strains of the virus. Substantial research has been carried over a past few years for the development of a potential vaccine that has some ability to combat HIV. The results are not very encouraging and call for the development of more sophisticated and quicker techniques regarding the same. A promising remedy in this area is the use of reverse vaccinology approaches that includes various computational approaches for epitope prediction and their binding efficiency with broadly neutralizing antibodies (like VAXIGN, Vaccine CAD, Epi-Assembler, docking studies). Following the prediction of a possible vaccine by in silico methods, their efficacy can be evaluated by IFN- $\gamma$ ELISPOT assay, intracellular cytokine staining assay, virus neutralization assay, ELISA binding antibodies. Use of reverse vaccinology and immunoformatics in silico approaches will help in speeding up the time duration of vaccine development and will also reduce the cost.

\section{Acknowledgement}

I gratefully acknowledge Dr. Archana Tiwari, School of Biotechnology, Rajiv Gandhi Proudyogiki Vishwavidyalaya, for her support and valuable guidance.

\section{References}

1. UNAIDS Global facts and figures.

2. [No authors listed] (1995) UNAIDS: mission and roles. Glob AIDSnews: 2-3.

3. Letvin NL (1998) Progress in the development of an HIV-1 vaccine. Science 280: $1875-1880$.

4. Barroso H, Borrego P, Bártolo I, Marcelino JM, Família C, et al. (2011) Evolutionary and structural features of the $\mathrm{C} 2, \mathrm{~V} 3$ and $\mathrm{C} 3$ envelope regions underlying the differences in HIV-1 and HIV-2 biology and infection. PLoS One 6: e14548.

5. Berry N, Ariyoshi K, Jaffar S, Sabally S, Corrah T, et al. (1998) Low periphera blood viral HIV-2 RNA in individuals with high CD4 percentage differentiates HIV-2 from HIV-1 infection. J Hum Virol 1: 457-468.

6. Drylewicz J, Matheron S, Lazaro E, Damond F, Bonnet F, et al. (2008) Comparison of viro-immunological marker changes between HIV-1 and HIV-2infected patients in France. AIDS 22: 457-468.

7. Marlink R, Kanki P, Thior I, Travers K, Eisen G, et al. (1994) Reduced rate of disease development after HIV-2 infection as compared to HIV-1. Science 265 1587-1590.

8. Soares R, Foxall R, Albuquerque A, Cortesão C, Garcia M, et al. (2006) Increased frequency of circulating CCR $5+\mathrm{CD} 4+\mathrm{T}$ cells in human immunodeficiency virus type 2 infection. J Virol 80: 12425-12429.

9. Björling E, Scarlatti G, von Gegerfelt A, Albert J, Biberfeld G, et al. (1993) Autologous neutralizing antibodies prevail in HIV-2 but not in HIV-1 infection. Virology 193: 528-530.

10. de Silva TI, Cotten M, Rowland-Jones SL (2008) HIV-2: the forgotten AIDS virus. Trends Microbiol 16: 588-595.

11. Lizeng Q, Skott P, Sourial S, Nilsson C, Andersson SS, et al. (2003) Serum

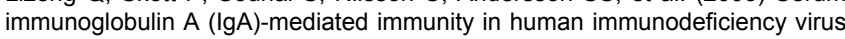
type 2 (HIV-2) infection. Virology 308: 225-232.

12. Rodriguez SK, Sarr AD, MacNeil A, Thakore-Meloni S, Gueye-Ndiaye A, et al. (2007) Comparison of heterologous neutralizing antibody responses of 
human immunodeficiency virus type 1 (HIV-1)- and HIV-2-infected Senegalese patients: distinct patterns of breadth and magnitude distinguish HIV-1 and HIV2 infections. J Virol 81: 5331-5338.

13. Shi Y, Brandin E, Vincic E, Jansson M, Blaxhult A, et al. (2005) Evolution of human immunodeficiency virus type 2 coreceptor usage, autologous neutralization, envelope sequence and glycosylation. J Gen Virol 86: 33853396.

14. Cavaleiro R, Brunn GJ, Albuquerque AS, Victorino RM, Platt JL, et al. (2007) Monocyte-mediated $\mathrm{T}$ cell suppression by HIV-2 envelope proteins. Eur J Immunol 37: 3435-3444.

15. Cavaleiro R, Sousa AE, Loureiro A, Victorino RM (2000) Marked immunosuppressive effects of the HIV-2 envelope protein in spite of the lower HIV-2 pathogenicity. AIDS 14: 2679-2686.

16. Grossman Z, Meier-Schellersheim M, Sousa AE, Victorino RM, Paul WE (2002) CD4+ T-cell depletion in HIV infection: are we closer to understanding the cause? Nat Med 8: 319-323.

17. Korber BT, Kunstman KJ, Patterson BK, Furtado M, McEvilly MM, et al. (1994) Genetic differences between blood- and brain-derived viral sequences from human immunodeficiency virus type 1-infected patients: evidence of conserved elements in the V3 region of the envelope protein of brain-derived sequences. Journal of Virology 68: 7467-7481.

18. Borrego P, Marcelino JM, Rocha C, Doroana M, Antunes F, et al. (2008) The role of the humoral immune response in the molecular evolution of the envelope C2, V3 and C3 regions in chronically HIV-2 infected patients. Retrovirology 5 : 78.

19. Skar H, Borrego P, Wallstrom TC, Mild M, Marcelino JM, et al. (2010) HIV2 genetic evolution in patients with advanced disease is faster than that in matched HIV-1 patients. J Virol 84: 7412-7415.

20. National Institute of Allergy and Infectious Diseases.

21. http://www.pnac.net.pk/Reports/FactSheets/English/FactSheet-1.pdf.

22. Peters BS, Conway K (2011) Therapy for HIV: past, present, and future. Adv Dent Res 23: 23-27.

23. Fultz PN (1997) AIDS and Other Manifestations of HIV Infection. (3rd edn), Newyork 201-215.

24. Girard M, Meignier B, Barré-Sinoussi F, Kieny MP, Matthews T, et al. (1995) Vaccine-induced protection of chimpanzees against infection by a heterologous human immunodeficiency virus type 1. J Virol 69: 6239-6248.

25. Letvin NL, King NW (1990) Immunologic and pathologic manifestations of the infection of rhesus monkeys with simian immunodeficiency virus of macaques. J Acquir Immune Defic Syndr 3: 1023-1040.

26. Myers G, Korber B, Berzofsky JA, Pavlakis GN, Smith RE (1993) A Compilation and Analysis of Nucleic Acid and Amino Acid Sequences. Human Retroviruses and AIDS Eds.

27. Igarashi T, Shibata R, Hasebe F, Ami Y, Shinohara K, et al. (1994) Persistent infection with SIVmac chimeric virus having tat, rev, vpu, env and nef of HIV type 1 in macaque monkeys. AIDS Res Hum Retroviruses 10: 1021-1029.

28. Luciw PA, Pratt-Lowe E, Shaw KE, Levy JA, Cheng-Mayer C (1995) Persisten infection of rhesus macaques with T-cell-line-tropic and macrophage-tropic clones of simian/human immunodeficiency viruses (SHIV). Proc Natl Acad Sci U S A 92: 7490-7494.

29. Li JT, Halloran M, Lord Cl, Watson A, Ranchalis J, et al. (1995) Persistent infection of macaques with simian-human immunodeficiency viruses. J Virol 69: 7061-7067.

30. Li J, Lord Cl, Haseltine W, Letvin NL, Sodroski J (1992) Infection of cynomolgus monkeys with a chimeric HIV-1/SIVmac virus that expresses the HIV-1 envelope glycoproteins. J Acquir Immune Defic Syndr 5: 639-646.

31. Reimann KA, Li JT, Veazey R, Halloran M, Park IW, et al. (1996) A chimeric simian/human immunodeficiency virus expressing a primary patient human immunodeficiency virus type 1 isolate env causes an AIDS-like disease after in vivo passage in rhesus monkeys. J Virol 70: 6922-6928.

32. Nishimura Y, Igarashi T, Donau OK, Buckler-White A, Buckler C, et al. (2004) Highly pathogenic SHIVs and SIVs target different CD4+ T cell subsets in rhesus monkeys, explaining their divergent clinical courses. Proc Natl Acad Sci U S A 101: 12324-12329.
33. Williams R, Bokhari S, Silverstein P, Pinson D, Kumar A et al. (2008) Nonhuman primate models of NeuroAIDS. J Neurovirol 14: 292-300.

34. Pauly-O'Neill S (1991) Questioning the use of invasive technology. Am J Nurs 91: $19-20$

35. Nitayaphan S, Pitisuttithum P, Karnasuta C, Eamsila C, de Souza M, et al. (2004) Safety and immunogenicity of an HIV subtype B and E prime-boos vaccine combination in HIV-negative Thai adults. J Infect Dis 190: 702-706.

36. Karnasuta C, Paris RM, Cox JH, Nitayaphan S, Pitisuttithum P, et al. (2005) Antibody-dependent cell-mediated cytotoxic responses in participants enrolled in a phase I/II ALVAC-HIVIAIDSVAX B/E prime-boost HIV-1 vaccine trial in Thailand. Vaccine 23: 2522-2529.

37. Kwong PD, Mascola JR, Nabel GJ (2012) The changing face of HIV vaccine research. J Int AIDS Soc 15: 17407

38. http://www.clinicaltrials.gov/ct2/show/study/NCT00865566?term=NCT008655 $66 \&$ rank=1.

39. De Groot AS, Marcon L, Bishop EA, Rivera D, Kutzler M, et al. (2005) HIV vaccine development by computer assisted design: the GAIA vaccine. Vaccine 23: $2136-2148$

40. Zembe L, Burgers WA, Jaspan HB, Bekker LG, Bredell H, et al. (2011) Intraand inter-clade cross-reactivity by HIV-1 Gag specific T-cells reveals exclusive and commonly targeted regions: implications for current vaccine trials. PLoS One 6: e26096.

41. Geldmacher C, Currier JR, Gerhardt M, Haule A, Maboko L, et al. (2007) In a mixed subtype epidemic, the HIV-1 Gag-specific T-cell response is biased towards the infecting subtype. AIDS 21: 135-143.

42. McKinnon LR, Ball TB, Kimani J, Wachihi C, Matu L, et al (2005) Cross-clade CD8(+) T-cell responses with a preference for the predominant circulating clade. J Acquir Immune Defic Syndr 40: 245-249.

43. Frahm N, Kaufmann DE, Yusim K, Muldoon M, Kesmir C, et al. (2007) Increased sequence diversity coverage improves detection of HIV-specific T cell responses. J Immunol 179: 6638-6650.

44. Rolland M, Frahm N, Nickle DC, Jojic N, Deng W, et al. (2011) Increased breadth and depth of cytotoxic T lymphocytes responses against HIV-1-B Nef by inclusion of epitope variant sequences. PLoS One 6: e17969.

45. Malhotra U, Nolin J, Mullins JI, McElrath MJ (2007) Comprehensive epitope analysis of cross-clade Gag-specific T-cell responses in individuals with early HIV-1 infection in the US epidemic. Vaccine 25: 381-390

46. Allen TM, Altfeld M, Yu XG, O'Sullivan KM, Lichterfeld M, et al. (2004) Selection, transmission, and reversion of an antigen-processing cytotoxic T-lymphocyte escape mutation in human immunodeficiency virus type 1 infection. J Virol 78 7069-7078.

47. Carlson JM, Brumme ZL (2008) HIV evolution in response to HLA-restricted CTL selection pressures: a population-based perspective. Microbes Infect 10 : 455-461.

48. Dong T, Zhang Y, Xu KY, Yan H, James I, et al. (2011) Extensive HLA-driven viral diversity following a narrow-source HIV-1 outbreak in rural China. Blood 118: $98-106$

49. Kawashima Y, Pfafferott K, Frater J, Matthews P, Payne R, et al. (2009) Adaptation of HIV-1 to human leukocyte antigen class I. Nature 458: 641-645.

50. Kiepiela P, Leslie AJ, Honeyborne I, Ramduth D, Thobakgale C, et al. (2004) Dominant influence of HLA-B in mediating the potential co-evolution of HIV and HLA. Nature 432: 769-775.

51. Starcich BR, Hahn BH, Shaw GM, McNeely PD, Modrow S, et al. (1986) Identification and characterization of conserved and variable regions in the envelope gene of HTLV-III/LAV, the retrovirus of AIDS. Cell 45: 637-648.

52. DeVico A, Fouts T, Lewis GK, Gallo RC, Godfrey K, et al. (2007) Antibodies to CD4-induced sites in HIV gp120 correlate with the control of SHIV challenge in macaques vaccinated with subunit immunogens. Proc Natl Acad Sci U S A 104: $17477-17482$

53. Doms RW, Moore JP (2000) HIV-1 membrane fusion: targets of opportunity. J Cell Biol 151: F9-14.

54. Fenouillet E, Barbouche R, Jones IM (2007) Cell entry by enveloped viruses: redox considerations for HIV and SARS-coronavirus. Antioxid Redox Signal 9 : 1009-1034. 
Citation: Saxena R, Mishra G, Diwan B, Tiwari A (2013) HIVIAIDS Vaccine Design and Strategies. J Vaccines Vaccin 4: 190. doi:10.4172/21577560.1000190

55. Wyatt R, Sodroski J (1998) The HIV-1 envelope glycoproteins: fusogens, antigens, and immunogens. Science 280: 1884-1888.

56. Walker LM, Phogat SK, Chan-Hui PY, Wagner D, Phung P, et al. (2009) Broad and potent neutralizing antibodies from an African donor reveal a new HIV-1 vaccine target. Science 326: 285-289.

57. Walker LM, Huber M, Doores KJ, Falkowska E, Pejchal R, et al. (2011) Broad neutralization coverage of HIV by multiple highly potent antibodies. Nature 477: 466-470

58. Tagliamonte M, Tornesello ML, Buonaguro FM, Buonaguro L (2011) Conformational HIV-1 envelope on particulate structures: a tool for chemokine coreceptor binding studies. J Transl Med 9 Suppl 1: S1.

59. Buonaguro L, Buonaguro FM, Tornesello ML, Mantas D, Beth-Giraldo E, et al. (2001) High efficient production of Pr55(gag) virus-like particles expressing multiple HIV-1 epitopes, including a gp120 protein derived from an Ugandan HIV-1 isolate of subtype A. Antiviral Res 49: 35-47.

60. Gheysen D, Jacobs E, de Foresta F, Thiriart C, Francotte M, et al. (1989) Assembly and release of HIV-1 precursor Pr55gag virus-like particles from recombinant baculovirus-infected insect cells. Cell 59: 103-112.

61. Wagner R, Deml L, Fliessbach H, Wanner G, Wolf H (1994) Assembly and extracellular release of chimeric HIV-1 Pr55gag retrovirus-like particles. Virology 200: 162-175

62. Yamshchikov GV, Ritter GD, Vey M, Compans RW (1995) Assembly of SIV virus-like particles containing envelope proteins using a baculovirus expression system. Virology 214: 50-58.

63. Bachmann MF, Lutz MB, Layton GT, Harris SJ, Fehr T, et al. (1996) Dendritic cells process exogenous viral proteins and virus-like particles for class presentation to CD8+ cytotoxic T lymphocytes. Eur J Immunol 26: 2595-2600.

64. Deml L, Kratochwil G, Osterrieder N, Knüchel R, Wolf H, et al. (1997) Increased incorporation of chimeric human immunodeficiency virus type $1 \mathrm{gp} 120$ proteins into Pr55gag virus-like particles by an Epstein-Barr virus gp220/350-derived transmembrane domain. Virology 235: 10-25.

65. Yao Q, Bu Z, Vzorov A, Yang C, Compans RW (2003) Virus-like particle and DNA-based candidate AIDS vaccines. Vaccine 21: 638-643.

66. Reimann J, Schirmbeck R (1999) Alternative pathways for processing exogenous and endogenous antigens that can generate peptides for MHC class I-restricted presentation. Immunol Rev 172: 131-152.

67. Zhang X, Wang X, Zhao D, Meng X, Zhao X, et al. (2011) Design and immunogenicity assessment of HIV-1 virus-like particles as a candidate vaccine. Sci China Life Sci 54: 1042-1047.

68. Lassen K, Han Y, Zhou Y, Siliciano J, Siliciano RF (2004) The multifactoria nature of HIV-1 latency. Trends Mol Med 10: 525-531.

69. Koup RA, Douek DC (2011) Vaccine design for CD8 T lymphocyte responses Cold Spring Harb Perspect Med 1: a007252.

70. Pantaleo G, Esteban M, Jacobs B, Tartaglia J (2010) Poxvirus vector-based HIV vaccines. Curr Opin HIV AIDS 5: 391-396. 